\title{
ARTICLE OPEN Diffusive processes in aqueous glass dissolution
}

\author{
Thomas L. Goût $\mathbb{D}^{1 *}$, Sambuddha Misra ${ }^{1,2}$, Edward T. Tipper ${ }^{1}$, Madeleine S. Bohlin ${ }^{1}$, Rui Guo ${ }^{1}$ and lan Farnan $\mathbb{D}^{1}$
}

High level nuclear waste is often immobilised in a borosilicate glass for disposal. However, this glass corrodes in contact with aqueous solutions. To predict radionuclide releases from wasteforms, their dissolution mechanisms must be understood. Understanding glass dissolution mechanisms presents a challenge across numerous other disciplines and many glass dissolution models still remain conflicted. Here we show that diffusion was a significant process during the later stages of dissolution of a simplified waste glass but was not evidenced during the initial stages of dissolution. The absence of measurable isotopic fractionation in solution initially supports models of congruent dissolution. However, the solution becoming isotopically lighter at later times evidences diffusive isotopic fractionation and opposes models that exclude diffusive transport as a significant mechanism. The periodically sampled isotopic methodologies outlined here provide an additional dimension with which to understand glass dissolution mechanisms beyond the usual measurement of solution concentrations and, post-process, nano-scale analysis of the altered glass.

npj Materials Degradation (2019)3:39; https://doi.org/10.1038/s41529-019-0102-5

\section{INTRODUCTION}

The safe disposal of vitrified nuclear waste arising from the reprocessing of spent nuclear fuel requires that dissolution rates within geological disposal facilities are accurately modelled and aqueous dissolution mechanisms are well understood. ${ }^{1}$ In recent years, a model of silicate mineral weathering, herein referred to as the 'interfacial dissolution-precipitation model', has been applied to silicate glasses. ${ }^{2-4}$ This model challenged not only the structure of the alteration layers formed as predicted by established models of glass dissolution, ${ }^{5,6}$ but also the long-held hypothesis that interdiffusion (hydration of the glass and ion-exchange reactions between protonated water species and glass species) is a ratelimiting mechanism during the initial moments of dissolution and again at high reaction progress. ${ }^{7}$ Considering a timespan of at least one million years, ${ }^{8}$ the rates of residual glass alteration would be different if dissolution was congruent through network hydrolysis from a supersaturated interfacial film of water, hypothesised by the interfacial dissolution-precipitation model, ${ }^{3,4}$ or if dissolution was incongruent as predicted by diffusion-based models; some of which hypothesise interdiffusion reactions and the precipitation of secondary phases control the residual rate of glass dissolution. ${ }^{1,7,9}$ In this case, interdiffusion reactions across a highly passivating, hydrated, altered glass interphase would be rate limiting.

In the weathering of natural systems, Li potentially fractionates through two isotope effects: kinetic isotope effects during dissolution of the primary phase or equilibrium isotope effects where $\mathrm{Li}$ is incorporated into or adsorbed onto secondary phases. $^{10-12}$ Kinetic isotope effects are associated with rapid, unidirectional processes wherein the lighter isotope is preferentially transported across a phase boundary (such as in diffusion) or through a phase (such as in evaporation) due to its higher velocity. ${ }^{13}$ While the large mass difference between ${ }^{6} \mathrm{Li}$ and ${ }^{7} \mathrm{Li}$ ( 15\%) should be very sensitive to kinetic isotope effects, no such effects have been observed during the dissolution of the primary phase during basaltic glass dissolution. ${ }^{11,14-16}$ Equilibrium isotope effects occur due to differences in isotopic masses effecting differences in bond energy preferences. Molecules containing heavier isotopes will have a higher reduced mass, a lower frequency as defined by Hooke's law, a lower zero-point energy and so are more stable than molecules containing lighter isotopes. ${ }^{13}$ Consequently, the heavier isotope is preferentially partitioned into higher bond energy sites. ${ }^{17}$ For Li, longer bond lengths, less stiff bonds and lower bond energies are associated with higher coordination number sites. ${ }^{10,13}$ As such, when there is precipitation, ${ }^{6} \mathrm{Li}$ is preferentially partitioned into the higher $\mathrm{CN}$ octahedral and pseudo-hexagonal sites (CN of six) of clay secondary phases, ${ }^{7} \mathrm{Li}$ preferentially remains in solution (CN of four) ${ }^{10,18,19}$ and the solution becomes isotopically heavier with time. ${ }^{20-24}$ Further, Li can be adsorbed into the interlayer sites of smectites or onto the adsorption sites of gibbsite and ferrihydrite, although the former is not expected to be associated with any isotopic fractionation. ${ }^{10,14,18}$

Here, isotope fingerprinting techniques ${ }^{25}$ have been applied to glass leachates to probe whether the dissolution of a simplified simulant nuclear waste glass was rate-limited by diffusion. A seven-oxide borosilicate simplified glass analogue, ${ }^{6} \mathrm{Li}-\mathrm{Mg}-\mathrm{EM}$, was synthesised based on an existing Li-free analogue of a complex simulant Magnox (Mg-Al alloy fuel cladding) waste glass of $25 \mathrm{wt} \%$ waste loading. ${ }^{26}{ }^{6} \mathrm{Li}-\mathrm{Mg}-\mathrm{EM}$ was synthesised with a measured $\delta^{7} \mathrm{Li}$ of $-916.5 \pm 0.3 \%$ o $\left({ }^{7} \mathrm{Li} /{ }^{6} \mathrm{Li}\right.$ ratio of $\left.1.029 \pm 0.004\right)$.

Glass powders were leached at $90.0 \pm 0.1^{\circ} \mathrm{C}$ in deionised water, with leachate aliquots being taken in triplicate at intervals of $6 \mathrm{~h}$, 12 h, 7 days, 28 days and 98 days. After the 28-day aliquots were taken, the leachant in one of the leaching vessels was replaced with fresh deionised water before the vessel was placed back into the heaters for a further 70 days. The $\mathrm{pH}$ of the experiments was allowed to vary freely. Leachate aliquots underwent matrix purification and then Li isotope analysis to determine how the isotopic composition of the solutions evolved with time relative to the pristine glass.

\footnotetext{
Department of Earth Sciences, University of Cambridge, Downing Street, Cambridge CB2 3EQ, UK. ${ }^{2}$ Centre for Earth Sciences, Indian Institute of Science, Bangalore 560012, India. *email: tlg29@cam.ac.uk
} 

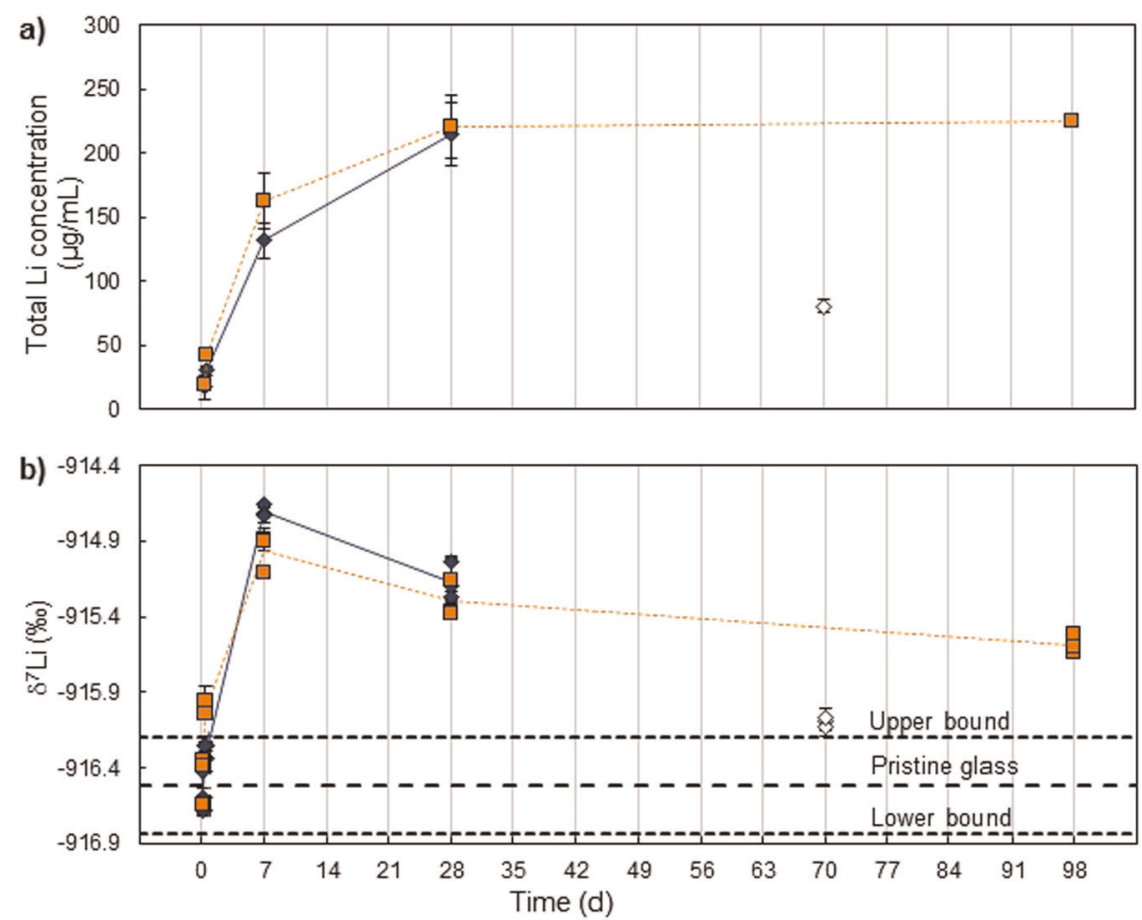

Fig. 1 Temporal evolution of the Li concentration and the Li isotopic composition of the leachates. The mass spectrometric (ICP-MS) results display the total concentration of $\mathrm{Li}$ in the leachates (background, drift and dilution factor corrected) with one s.d. errors a and the MC-ICP-MS results show the $\mathrm{Li}$ isotopic composition $\left(\delta^{7} \mathrm{Li}\right)$ of the same leachates and the pristine glass with two s.d. errors $\mathbf{b}$. In a, the solid and dotted lines and markers represent the mean values. In $\mathbf{b}$, individual analyses are plotted for each of the triplicate leachates with the mean values indicated by the solid and dotted lines. The blue solid line with diamond markers and the orange dotted line with square markers in both figures represent the two datasets of the duplicated experiments. The open diamond markers represent the same experiment as the blue filled diamond markers in which the leachant was refreshed in one vessel after the sampling of the 28 day aliquots followed by a further 70 days of leaching in fresh DI water (98 days total dissolution). The central black dashed line in $\mathbf{b}$ denotes the measured pristine Li isotopic composition of ${ }^{6} \mathrm{Li}-\mathrm{Mg}-\mathrm{EM}$, with the lines above and below this denoting the two s.d. error on this measurement.

\section{RESULTS}

Initially congruent dissolution

After $6 \mathrm{~h}$ of dissolution, significant amounts of Li were leached into solution (Fig. 1a), the alteration layers were estimated to be $0.3 \mu \mathrm{m}$ thick (from boron release) and an estimated $1.6 \%$ of the glass was altered (Fig. 2). However, the release of Li did not correlate with any measurable isotopic fractionation (Fig. 1b), with the leachate's isotopic composition being within error of the pristine glass isotopic composition. If the nature of dissolution were incongruent dominantly through interdiffusion reactions during this initial regime, the leachates would be isotopically lighter than the pristine glass ( $\delta^{7} \mathrm{Li}$ would decrease) due to kinetically enhanced ${ }^{6} \mathrm{Li}$ diffusion through the hydrated glass layer. This demonstrated that the initial stage of dissolution was congruent.

\section{Secondary phase precipitation}

Between $6 \mathrm{~h}$ and 7 days, the average estimated alteration layer thickness grew from 0.3 to $3.1 \mu \mathrm{m}$ and the estimated amount of glass altered rose from 1.6 to $15.4 \%$ (Fig. 2). The leachates becoming isotopically heavier with time (increase of the $\delta^{7} \mathrm{Li}$ ) during the initial rate regime is consistent with congruent dissolution alongside the dominant removal of Li from solution. During this time, the $\mathrm{Li}$ to $\mathrm{B}$ and $\mathrm{Li}$ to $\mathrm{Na}$ ratios in solution decreased (Fig. 3a, c respectively). Neither B nor Na are completely retained by the leachant. Although $B$ is known to adsorb onto the surface of clays with a strong $\mathrm{pH}$ dependency, ${ }^{27}$ significant masses of $\mathrm{B}$ are not expected to co-precipitate from solution during glass dissolution. ${ }^{28}$ However, some $\mathrm{Na}$ is also expected to be incorporated into a sodium silicate hydrate phase. ${ }^{29,30}$ The combined decreasing $\mathrm{Li}$ to $\mathrm{Na}$ and $\mathrm{Li}$ to $\mathrm{B}$ ratios with time are consistent with a Li-bearing phase being precipitated from solution onto the surface of the glass. This phenomenon was confirmed through static ${ }^{6} \mathrm{Li}^{1}{ }^{1} \mathrm{H}$ cross polarisation nuclear magnetic resonance (CP-NMR) experiments on a glass sample of the same elemental composition leached under similar conditions. $^{30,31}$ This technique transfers proton nuclear magnetic polarisation via a through space coupling to adjacent ${ }^{6} \mathrm{Li}$ atoms for NMR detection at the ${ }^{6} \mathrm{Li}$ Larmor frequency and so it selectively probes $\mathrm{Li}$ in the alteration layers or secondary phases. A small but measurable signal was observed from the protonated alteration layers and demonstrated that Li was being incorporated into a secondary phase or the alteration layers after just 7 days (Fig. 4). This was consistent with the observation of a Li-bearing clay secondary phase layer forming on the surface of an immobilised low-activity waste glass during long-term dissolution in a pressurised, undersaturated environment at a high glass surface area to leachant volume ratio. ${ }^{32}$

The preferential incorporation of ${ }^{6} \mathrm{Li}$ into these secondary phases resulted in the leachates becoming significantly enriched in ${ }^{7} \mathrm{Li}$ with time between $6 \mathrm{~h}$ and 7 days through an equilibrium isotope effect (Fig. 1b). ${ }^{14,15}$ The increasing $\delta^{7} \mathrm{Li}$ in solution, preceded by no measurable isotopic fractionation, suggested dissolution continued to be congruent during this initial dissolution regime and no measurable diffusive isotopic fractionation was present to offset this increase. Alternatively, diffusive isotopic fraction could have been masked by secondary phase precipitation, although this was considered unlikely due to the initial absence of diffusive isotopic fractionation. During this time, the $\mathrm{Li}$ to $\mathrm{Mg}$ ratio in solution increased (Fig. $3 b$ ), suggesting that $\mathrm{Li}$ is incorporated into secondary phases at a much slower rate than Mg. Based upon observations of a macroporous Mg-silicate layer wholly covering the surfaces of glass particles of the same 

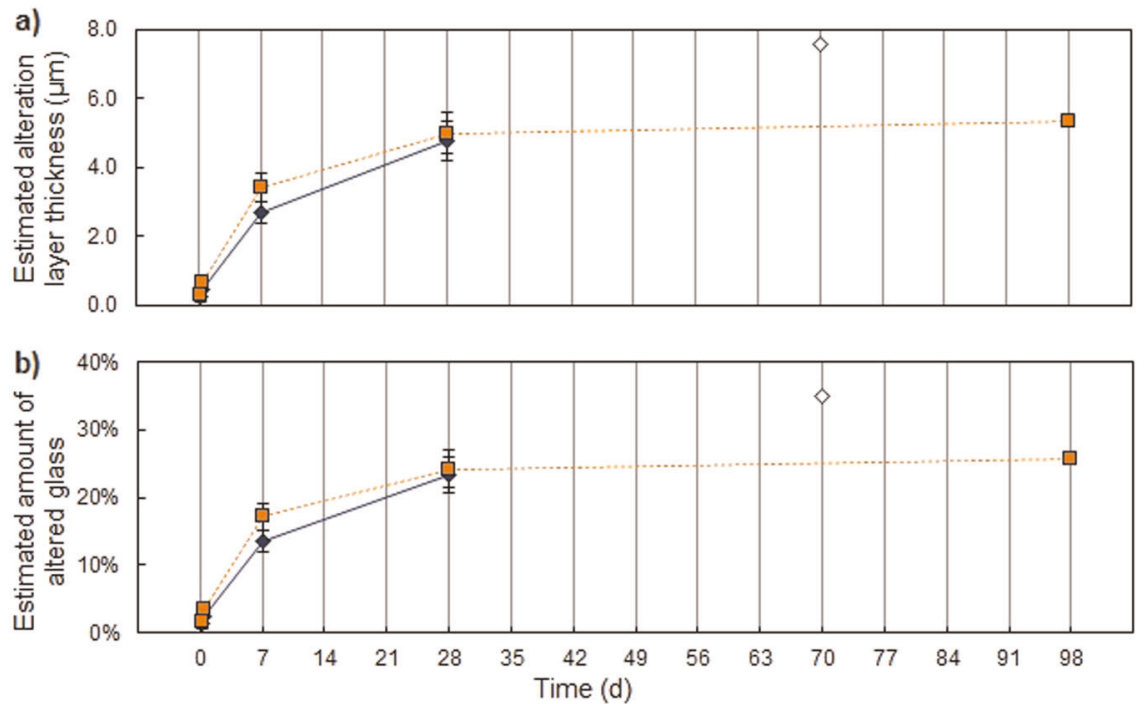

Fig. 2 Temporal evolution of the estimated thickness of the alteration layers and amount of glass altered. The average estimated thickness of the alteration layers $\mathbf{a}$ and estimated amount of glass altered $\mathbf{b}$ from the total concentrations of B leached into solution. Points are plotted as the average of triplicate leachate measurements with errors calculated as one s.d. of each set of triplicate aliquot measurements taken from each vessel at each time. The blue solid line with diamond markers and the orange dotted line with square markers in both figures represent the two datasets of the duplicated experiments. The open diamond markers represent the same experiment as the filled blue diamond markers in which the leachant was refreshed in one vessel after the sampling of the 28 day aliquots followed by a further 70 days of leaching in fresh DI water (98 days total dissolution).

elemental composition (not enriched in ${ }^{6} \mathrm{Li}$ ) after dissolution in a similar study under similar conditions to those used herein, ${ }^{30}$ it could be expected that $\mathrm{Li}$ is incorporated into such a secondary phase; either through $\mathrm{Li}$ substituting for $\mathrm{Mg}$ into this secondary phase due to their similar ionic radii or due to this secondary phase inherently containing significant fractions of $\mathrm{Li}$ by being the amorphous precursor to a Li-containing clay such as a hectorite. ${ }^{33}$

\section{Diffusive processes}

A different process began operating in the later stage of dissolution. After 7 days, the $\delta^{7} \mathrm{Li}$ in solution had reached a maximum and the solution then started to become enriched in ${ }^{6} \mathrm{Li}$ with time (Fig. 1b). If dissolution were congruent and secondary phase precipitation continued, then only equilibrium isotope effects would be occurring and the solution would continue to be enriched in ${ }^{7} \mathrm{Li}$ with time. In such dissolution models of congruent glass dissolution which exclude diffusion as a rate-limiting mechanism, only the dissolution of the already formed ${ }^{6} \mathrm{Li}$-rich secondary phases or dissolution of the pristine glass unaccompanied by further equilibrium isotope effects through secondary phase precipitation could make the solution isotopically lighter with time. As these secondary phases were formed from the leachant and no notable changes in the leaching vessel environment took place between 7 and 28 days, it seems implausible that these secondary phases would spontaneously dissolve without an external driving force. Additionally, although the $\mathrm{Li}$ to $\mathrm{Na}$ and $\mathrm{Li}$ to $\mathrm{B}$ ratios (Fig. 3) decreased at a slower rate during this period compared to the interval between $6 \mathrm{~h}$ and 7 days, this observed decreasing trend suggested that the removal of Li from solution continued during the later dissolution regimes. The continued removal of Li from solution was confirmed through ${ }^{6} \mathrm{Li}-{ }^{1} \mathrm{H}$ CP-NMR of a sample leached for 112 days at $90^{\circ} \mathrm{C}$ in a similar study, ${ }^{31}$ which showed Li continued to be incorporated into secondary phases between 7 and 112 days (Fig. 4). Therefore, the enrichment of ${ }^{6} \mathrm{Li}$ in solution was attributed to kinetic isotopic fractionation due to the enhanced diffusive transport of ${ }^{6} \mathrm{Li}$ out of the glass over ${ }^{7} \mathrm{Li}$.

The magnitude of kinetic isotopic fractionation due to the diffusion of Li was large enough to entirely offset the heavy equilibrium isotopic fractionation due to the continued precipitation of secondary phases and enrich the solution in ${ }^{6} \mathrm{Li}$ with time. This is despite a slowed rate of glass dissolution as shown by the $\mathrm{Li}$ concentrations in solution (Fig. 1a). The evolution of the leachates back towards the bulk isotopic composition, coupled with only a small change in Li concentration between 7 and 28 days (also 98 days in the non-refreshed experiment) is well illustrated using an isotope-concentration cross plot (Fig. 5). During this time the average estimated alteration layer thickness and estimated amount of glass altered grew from $3.1 \mu \mathrm{m}$ and $15.4 \%$ to $4.9 \mu \mathrm{m}$ and $23.8 \%$ respectively (Fig. 2 ).

During the extended leaching for an additional 70 days, the leachates from the 'refreshed leachant experiment' had lower $\mathrm{Li}$ concentration than the levels observed after 7 days of initial dissolution of the pristine glass (Figs $1 \mathrm{a}$ and 5 ). This demonstrates that a passivating altered layer component was formed after 28 days which was able to retain its passivating nature after being significantly disturbed through leachant renewal. As such, this observation is consistent with other dissolution experiments involving solution renewal. ${ }^{34}$ According to this study, this passivating component is expected to form between 7 and 28 days, as is consistent with the $\mathrm{Si}$ concentration in solution reaching an apparent steady-state value during this time (Supplementary Fig. 1). In this time, the estimated alteration layer thickness in the refreshed leachant experiment grew significantly by $2.8 \mu \mathrm{m}$ from 4.8 to $7.6 \mu \mathrm{m}$, compared to an increase of $0.3 \mu \mathrm{m}$ from 5.0 to $5.3 \mu \mathrm{m}$ in the non-refreshed leachant experiment (Fig. 2a).

\section{DISCUSSION}

Figure 6 displays theoretical Li isotopic signatures of the leachates alongside theoretical cross-sections of leached glass after dissolution for the two conflicting models of dissolution. The diffusionbased model (Fig. 6a) assumes the hydrated glass is a relict glass structure denuded of mobile glass species and at long-duration is expected to contain the highly passivating, nanoporous alteration layer component. If dissolution strictly followed this model, diffusive isotopic fractionation would be visible after $6 \mathrm{~h}$ of dissolution. At long-duration, the isotopic signature of the 

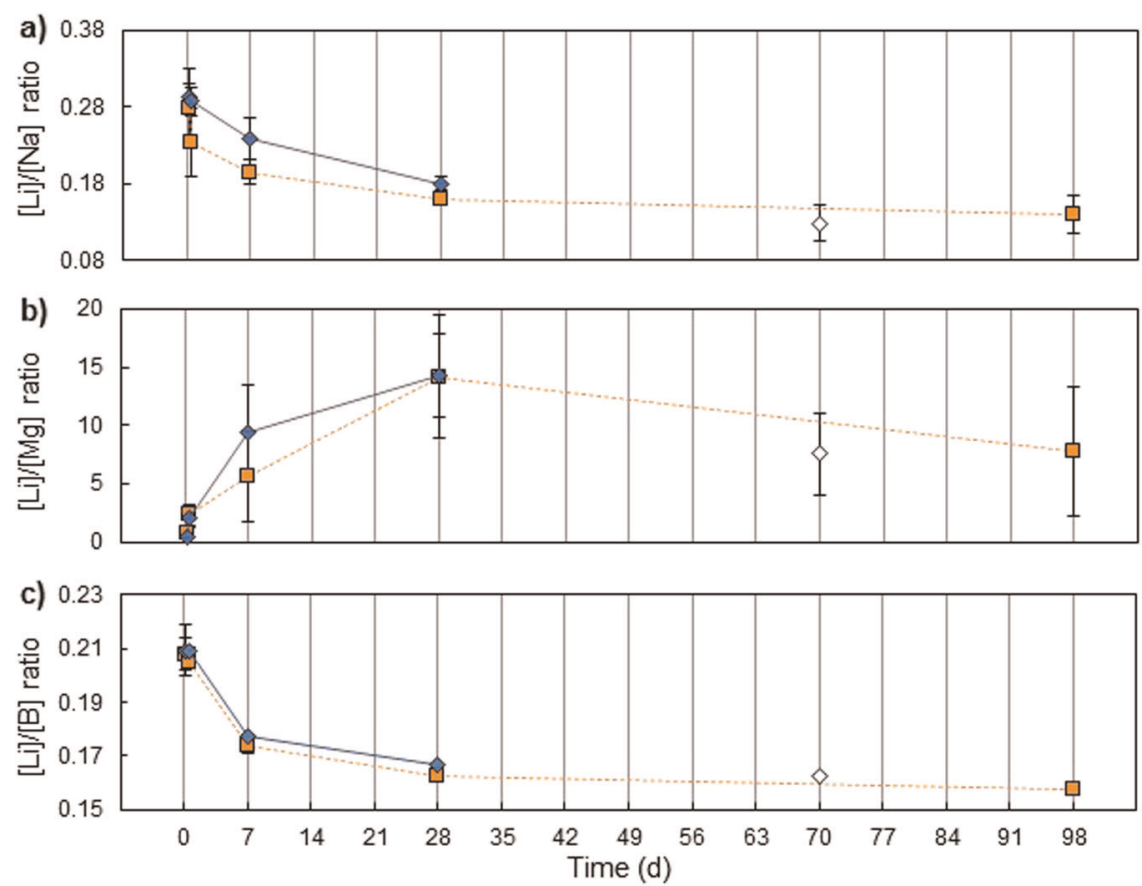

Fig. 3 Temporal evolution of select elemental ratios of the leachates. The $\mathrm{Li} / \mathrm{Na} \mathbf{a}, \mathrm{Li} / \mathrm{Mg} \mathbf{b}, \mathrm{Li} / \mathrm{B} \mathbf{c}$ ratios in the leachates, as calculated from their respective concentrations in solution in $\mu \mathrm{g} / \mathrm{ml}$ measured using ICP-MS. Each data point represents the average of the triplicate leachate measurements with errors given to one s.d. The blue solid line with diamond markers and the orange dotted line with square markers in all figures represent the two datasets of the duplicated experiments. The open diamond markers indicate the same experiment as the filled diamond markers in which in which the leachant was refreshed in one vessel after the 28 day aliquots were taken, before the glass was leached for further 70 days (98 days total dissolution).

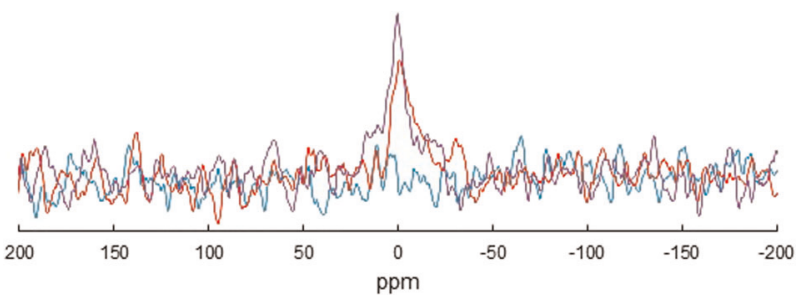

Fig. 4 Static ${ }^{6} \mathrm{Li}-{ }^{1} \mathrm{H}$ CP-NMR spectra of a sample leached for 7 days at $90^{\circ} \mathrm{C}$ (Red) and a sample leached for 112 days at $90^{\circ} \mathrm{C}$ (Purple) in static batch dissolution experiments ${ }^{31}$ compared with the spectrum of the pristine glass (Cyan). The glass composition was the same as the glass used in the isotopic study but was not enriched in ${ }^{6} \mathrm{Li}^{31}$ Spectra were normalised to the mass of sample analysed and the number of repetitions.

leachates could be expected to evolve following the observed trend due to the passivating alteration layer component inhibiting dissolution. ${ }^{1,7}$ Contrastingly, the interfacial dissolutionprecipitation model predicts consistently congruent dissolution with alteration layers which have precipitated from a supersaturated interfacial film of water (Fig. 6b). In this model, the isotopic signatures of the leachates would initially be within error of that of the pristine glass, but the leachates would continue to become isotopically heavier with time after 7 days as Li-bearing secondary phase continued to precipitate., ${ }^{2,3}$

The passivating altered layer component inhibited glass dissolution. The significant diffusive isotopic fractionation measured in solution coinciding with this layers' formation demonstrated that glass and water species are forced to diffuse across this layer to and from the pristine glass interface; presumably through its tight nanoporous structure. ${ }^{7,28}$ This process results in the lighter isotopes of glass species diffusing out of this layer faster due to their lower mass. That is, the leachates becoming enriched in ${ }^{6} \mathrm{Li}$ with time after 7 days are consistent with models of glass dissolution which predict the residual rate of dissolution is controlled by diffusion across a highly passivating altered layer component and the consumption of this hydrated glass layer through hydrolysis fuelled by secondary phase precipitation. ${ }^{7}$ In this view, while the glass alters at its residual rate, the inward diffusive transport of water species to the pristine glass interface presents a rate limiting mechanism and the isotopes of all glass species which outwardly diffuse through this layer leach from the glass incongruently. As such, this dissolution behaviour is consistent with the isotopic signatures which could be expected to be produced by a diffusion-based dissolution model at longduration (Fig. 6a) and is in agreement with isotope tracing experiments performed on the simplified analogue glass composition 'International Simple Glass'. ${ }^{35,36}$

Appearing to contradict the diffusive isotopic fractionation observed in the later dissolution regimes, the absence of isotopic fractionation at short duration was consistent with models of congruent glass dissolution (Fig. 6b). However, the high dissolution temperature and rapid leaching of species from the glass during the initial moments of dissolution might have resulted in interdiffusion only controlling the rate of alteration for mere seconds or minutes. Consequently, while it was shown that dissolution during the initial $6 \mathrm{~h}$ was congruent or virtually congruent, it is not known whether this was preceded by a negligibly short period of incongruent dissolution through interdiffusion reactions insufficient to produce measurable diffusive isotopic fractionation.

The decreasing isotope ratios in solution after 7 days of dissolution provided evidence for diffusion partly controlling the residual rate of alteration. However, this experiment alone does not allow us to rank models of glass dissolution. While the interfacial dissolution-precipitation model excluded interdiffusion reactions and the formation of a passivating relict hydrated glass structure as rate limiting mechanisms, ${ }^{3,4}$ a later version of this 


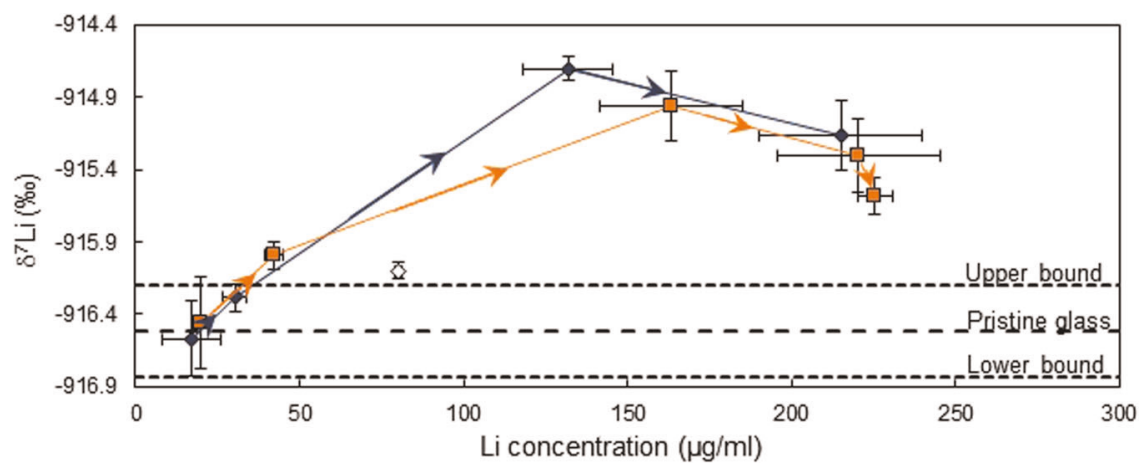

Fig. 5 Evolution of the leachate Li isotopic composition as a function of Li concentration change. Cross plot of the average Li isotopic composition of the leachates $\left(\delta^{7} \mathrm{Li}\right)$ measured using MC-ICP-MS for each triplicate (also given in Fig. $\left.1 \mathrm{~b}\right)$ against the total Li concentration in solution (also given in Fig. 1a). Errors are given to two s.d. on the isotopic data and one s.d. on the concentration data, as calculated from the triplicate aliquot measurements. The blue line with diamond markers and the orange line with square markers represent the two datasets of the duplicated experiments. The open diamond marker indicates the same experiment as the filled diamond markers in which the leachant was refreshed in one vessel after the 28-day aliquots were taken, before the glass was leached for further 70 days (98 days total dissolution). The central dashed black line indicates the pristine glass isotopic composition with the lines above and below this representing the two s.d. error on this measurement, as calculated from the triplicate MC-ICP-MS measurements of the four full-procedure alkali fusion replicates of the pristine glass.

model hypothesised a passivating altered layer component may precipitate behind a congruent dissolution front which could limit transport due to diffusion. ${ }^{2}$ Therefore, despite challenging models which exclude diffusion and the formation of a passivating alteration layer as significant dissolution mechanisms at high reaction progress, this evidence for diffusion being a rate-limiting mechanism is insufficient to elucidate whether this diffusive isotopic fractionation is the result of interdiffusion reactions across a passivating densified hydrated glass layer, or if it is caused by rate-limiting diffusion across a passivating precipitated layer behind an interfacial thin-film of water and a congruent dissolution front. However, it should be noted that the techniques described here afforded clear demonstration of diffusive processes, which otherwise would be difficult to detect with leachate concentration measurements and nano-scale measurements of elemental profiles within the alteration layers. ${ }^{3,9,28}$ As such, these techniques may be applied to investigate the isotopic signatures of other elements, such as B, in order to distinguish between these two conflicting dissolution models.

\section{METHODS}

Sample preparation

The ${ }^{6} \mathrm{Li}-\mathrm{Mg}$-EM glass (of nominal mol\% composition $3.24 \% \mathrm{Al}_{2} \mathrm{O}_{3}, 18.33 \%$ $\mathrm{B}_{2} \mathrm{O}_{3}, 1.14 \% \mathrm{La}_{2} \mathrm{O}_{3}, 2.56 \%{ }^{6} \mathrm{Li}_{2} \mathrm{O}, 2.56 \%{ }^{7} \mathrm{Li}_{2} \mathrm{O}, 8.69 \% \mathrm{MgO}, 5.11 \% \mathrm{Na}_{2} \mathrm{O}$ and $58.37 \% \mathrm{SiO}_{2}$ ) was prepared as a single batch from precursor powders which were dried at $90^{\circ} \mathrm{C}: \mathrm{Al}_{2} \mathrm{O}_{3}(99.99 \%), \mathrm{B}_{2} \mathrm{O}_{3}(99.98 \%), \mathrm{La}_{2} \mathrm{O}_{3}(99.999 \%)$, $\mathrm{Li}_{2} \mathrm{CO}_{3}\left(99.998 \%\right.$, assumed natural abundance of $\delta^{7} \mathrm{Li}$ ), $\mathrm{Li}_{2} \mathrm{CO}_{3}$ (Euriso-top, $95.77 \%{ }^{6} \mathrm{Li}$ atoms), $\mathrm{MgO}(99.99 \%)$, anhydrous $\mathrm{Na}_{2} \mathrm{~B}_{4} \mathrm{O}_{7}(99.95 \%)$ and $\mathrm{SiO}_{2}$ $(99.9 \%)$. These precursors were melted in a $90 \% \mathrm{Pt} 10 \% \mathrm{Rh} 200 \mathrm{ml}$ crucible inside a laboratory chamber furnace (Lenton UAF 16/10) at a rate of $10^{\circ} \mathrm{C} /$ min from room temperature to $750^{\circ} \mathrm{C}$, held for $3 \mathrm{~h}$, then heated to $1500^{\circ} \mathrm{C}$. The glass was poured onto room temperature graphite-coated steel plates then, upon cooling to room temperature, the glass was crushed to a fine powder with an agate mortar and pestle. This powder then underwent the same heating procedure again but without a $3 \mathrm{~h}$ hold and was poured onto $250^{\circ} \mathrm{C}$ graphite-coated steel plates then cooled for $2 \mathrm{~h}$. After which, the plates were no longer heated and the glass cooled for another $2 \mathrm{~h}$ before being annealed at $550^{\circ} \mathrm{C}$ for $2 \mathrm{~h}$.

The glass samples were crushed in an agate mortar and pestle, and sieved according the hand sieving procedure outlined in ASTM PCT-B C1285-1414 ${ }^{37}$ using $75 \mu \mathrm{m}$ and $150 \mu \mathrm{m}$ stainless steel test sieves. Visible contaminants and magnetic particles were removed, before the glass was washed in absolute ethanol: the glass powder was placed into a $60 \mathrm{ml}$ PTFE beaker and forcefully squirted with ethanol in a circular motion to approximately 1.5 times the volume of the glass powder, swirled for $10 \mathrm{~s}$, left to settle for $15 \mathrm{~s}$ and then the ethanol was decanted. This was repeated twice more but on the third time the ethanol was not decanted, but instead the beaker was placed into an ultrasonic bath for $2 \mathrm{~min}$. The ethanol was subsequently decanted and the entire process was repeated until the decanted ethanol appeared clear or a minimum of four times in total. The washed glass was then dried in a box oven at $90^{\circ} \mathrm{C}$ for over $16 \mathrm{~h}$ before being checked again with a magnet.

\section{Density measurements}

The density of ${ }^{6} \mathrm{Li}-\mathrm{Mg}$-EM was characterised using Archimedes' Principle in triplicate using approximately $1 \mathrm{~g}$ pieces of glass with no visible defects. An analytical balance (Ohaus Pioneer) with a weigh-below hook and a length of wire with a beaker of room temperature DI were used in the measurements. The density of ${ }^{6} \mathrm{Li}-\mathrm{Mg}$-EM was calculated to be $2.47 \pm$ $0.03 \mathrm{gcm}^{-3}$.

\section{X-ray powder diffraction}

Approximately $100 \mathrm{mg}$ of washed and sized ${ }^{6} \mathrm{Li}-\mathrm{Mg}$-EM was analysed for crystalline phases using an X-ray diffractometer (Bruker D8 Advance). A Cu $\mathrm{K}$-a wavelength was used with a near sample aperture slit size of $0.600 \mathrm{~mm}$. The powder was mounted onto a circular glass slide using acetone, which was mounted onto a PMMA sample holder. A range of $10.0000^{\circ}$ to $60.0123^{\circ}(2 \theta)$ was analysed in 978 steps of $0.0511^{\circ}$. The sample was found to be amorphous (Supplementary Fig. 2).

\section{Laser diffraction analysis}

A laser diffraction analyser (Malvern Instruments Mastersizer E) was used for particle size analysis. An enclosed cell with PTFE magnetic stirrer filled with absolute ethanol was placed in front of a $300 \mathrm{~mm}$ focal length lens. A beam length of $14.3 \mathrm{~mm}$ was used to analyse a distribution of $1.2 \mu \mathrm{m}$ to $600 \mu \mathrm{m}$. Approximately $75 \mathrm{mg}$ of sample was added to the cell (45000 particles) and the particle size distribution was measured. An obscuration of $0.125 \%$ and residual less than $2.000 \%$ were targeted. A uniform particle size distribution was obtained for ${ }^{6} \mathrm{Li}-\mathrm{Mg}$-EM with a median particle size of $132.75 \mu \mathrm{m}$ (Supplementary Fig. 3).

\section{Pristine glass composition}

Electron probe microanalysis (EPMA) was used to obtain the concentrations of all elements within the pristine glass except B and Li. Three pieces of ${ }^{6} \mathrm{Li}-\mathrm{Mg}$-EM were mounted in a two-part epoxy resin and polished using successive diamond pastes down to $3 \mu \mathrm{m}$ before being carbon coated. An electron microprobe (Cameca SX 100) was used with a beam diameter of $10 \mu \mathrm{m}$, acceleration voltage of $15 \mathrm{keV}$, and beam current of $20 \mathrm{nA} .12$ spots were analysed per piece of glass, selected in lines of 6 points each. Standards of jade for $\mathrm{Na}$, diopside for $\mathrm{Si}$, periclase for $\mathrm{Mg}$, corundrum for $\mathrm{Al}$, and lanthanum hexaboride for La were used. 

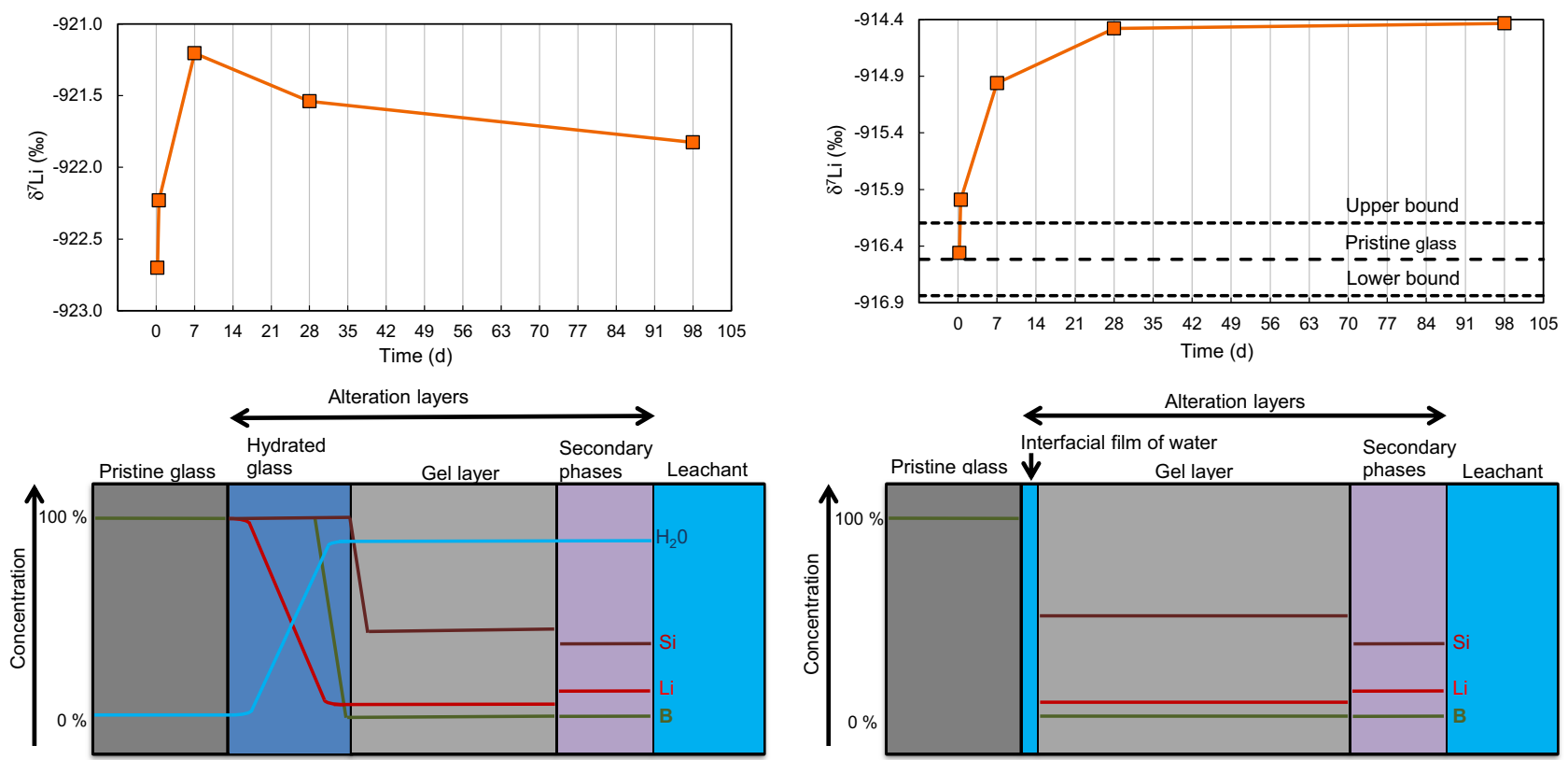

Fig. 6 Theoretical plots of the Li isotopic compositions of the leachates against time accompanied by theoretical elemental profiles within cross sections of leached glass at high reaction progress (approximately 28 days here). The theoretical structures of alteration layers and the cartoons of the evolution of the Li isotopic composition of the leachates according to a diffusion-based model a and the interfacial dissolution-precipitation model $\mathbf{b}$ are given. ${ }^{1-3,7}$ The cartoons of the isotopic evolution of the leachates in a assumes the isotopic composition of the leachate at $6 \mathrm{~h}$ is purely the result of kinetic isotopic fractionation from diffusion (pristine glass isotopic composition multiplied by the square root of the ratio of the masses of ${ }^{6} \mathrm{Li}$ and ${ }^{7} \mathrm{Li}$ ), after which time the leachates evolve following the observed profile. The cartoon of the evolution of the isotopic signature of the leachate in $\mathbf{b}$ follows the observed profile until $7 \mathrm{~d}$, whereafter it assumes secondary phase precipitation continues in the absence of diffusive isotopic fractionation at a rate depending upon the rate that Li is released into solution; in doing so, it is assumed the fraction of leached Li incorporated into the secondary phases and the composition of the secondary phases is constant throughout dissolution.

Laser ablation inductively coupled plasma mass spectrometry (LA-ICPMS) was used to determine the B and Li concentrations within the pristine glass. NIST610 was analysed to calibrate the elemental sensitivity of the run, with NIST614, NIST612 and BCR2-G analysed to veryify this calibration. A laser ablation system (ESI NWR193UC) with $193 \mathrm{~nm}$ Excimer laser using NeF gas connected to an ICP-MS (Perkin-Elmer NexION 350D) was used to analyse the resin mounted glass samples. Five 50 by $50 \mu \mathrm{m}$ squares were ablated on each of the three glass pieces. A fluence of $10 \mathrm{Jcm}^{-2}$, integration time of $5000 \mathrm{~ms}$, and dwell of $10 \mathrm{~ms}$ were used, taking $41 \mathrm{~s}$ to analyse each spot. $\mathrm{Li}$ and $\mathrm{B}$ concentrations were analysed assuming the glass had a ${ }^{7} \mathrm{Li} /{ }^{6} \mathrm{Li}$ ratio of 1.029 (equal to that measured), NIST610 had a ${ }^{7} \mathrm{Li} /{ }^{6} \mathrm{Li}$ ratio at natural abundance and the ${ }^{11} \mathrm{~B} /{ }^{10} \mathrm{~B}$ ratios of the glass and NIST610 were the same (Supplementary Table 1). To correct for analytical bias, concentrations were normalised to the $\mathrm{SiO}_{2}$ concentration measured using EPMA as an internal standard. All elements were well above their respective detection limits.

\section{Dissolution experiments}

A glass surface area to leachant volume ratio $(S A / V)$ of $2000 \mathrm{~m}^{-1}$ was targeted with $4.00 \pm 0.02 \mathrm{~g}$ of washed and sized $75 \mu \mathrm{m}$ to $150 \mu \mathrm{m}{ }^{6} \mathrm{Li}-\mathrm{Mg}$ EM powder and $42.5 \pm 0.4 \mathrm{ml}$ of type 1 deionised water $(18.2 \mathrm{M} \Omega \mathrm{cm}$ at $25^{\circ} \mathrm{C}$ ) leachant; a $\mathrm{V} / \mathrm{m}$ (leachant volume to glass mass ratio) of 10.0 would yield an SA/V of $2159 \mathrm{~m}^{-1}$ assuming a spherical particle diameter of $112.5 \mu \mathrm{m}$, and so more leachant was used. Static-batch dissolution experiments took place in duplicate at $90^{\circ} \mathrm{C}$ with duplicate blanks. Four acid cleaned $60 \mathrm{ml}$ PFA (Savillex) standard jars with fluid transfer port ( $3.175 \mathrm{~mm}$ inner diameter) lids (herein collectively referred to as leaching vessels) were sealed using a piece of acid cleaned PFA tubing $(3.175 \mathrm{~mm}$ outer diameter) held in place with ferrule nuts. The experiment was set up following ASTM PCT Test Method $\mathrm{B}^{25}$ protocol. Al blocks were pre-heated to $90.0 \pm 0.1^{\circ} \mathrm{C}$ inside two dry block heaters (QBH2, Grant Instruments). The fluid transfer lid design afforded rapid access to the leachant by acid cleaned PFA tubes attached to the end of $100 \mu$ l pipette tips. At intervals of $0.25,0.5,7,28$ and 98 days, the seals were temporarily removed, PFA tubes were inserted and $100 \mu \mathrm{l}$ aliquots in triplicate were taken from each leaching vessel. A fresh piece of acid-washed PFA tubing and pipette tip were used for each aliquot.

After the 28 day aliquots were taken, all four leaching vessels were weighed then one set of sample and blank vessels were quickly returned to the heaters. The other set had all their leachant replaced with approximately the same volume of fresh deionised water, then all four vessels were leached for a further 70 days. The glass was not dried before the leachant was refreshed. The SA/V stayed within $10 \%$ of the target $2000 \mathrm{~m}^{-1}$ throughout dissolution. The $\mathrm{pH}$ of the leachant before the experiment, the leachates after 28 days in the refreshed leachant experiment, and after a total leaching time of 98 days in all experiments were measured (Supplementary Fig. 4). Measurements took place on a FE20 FiveEasy benchtop pH metre with Mettler Toledo LE438 pH electrode calibrated using 7.00 and $10.01 \pm 0.01 \mathrm{pH}$ NIST traceable buffer solutions.

\section{Leachate concentration analysis}

The aliquots in $1.5 \mathrm{ml}$ vials were weighed on an analytical balance (Sartorius MC1 Analytic AC 210 s). All dilution acids were double distilled in a Teflon sub-boiling still. $1.0 \mathrm{ml}$ of $0.1 \mathrm{M} \mathrm{HNO}_{3}$ and $0.3 \mathrm{M} \mathrm{HF}$ was added to each vial, which were then mixed using a benchtop mixer (Fisher Scientific FB15013 Topmix) and inspected for precipitates before being weighed again. These masses were used to calculate a gravimetric dilution factor of $\sim 10$, depending upon the exact aliquot volume and degree of sample evaporation. Samples were diluted further using two 25 fold dilutions with $2 \% \mathrm{HNO}_{3}$ before undergoing a final 10 fold dilution with $0.1 \mathrm{M} \mathrm{HNO}_{3}$ and $0.3 \mathrm{M} \mathrm{HF}$ for a final dilution factor of approximately 62500 . All samples and blanks were analysed for the constituent elements of ${ }^{6} \mathrm{Li}-\mathrm{Mg}$-EM using ICPMS (Thermo Fisher Scientific Element XR); with isotopes ${ }^{6} \mathrm{Li},{ }^{7} \mathrm{Li},{ }^{10} \mathrm{~B},{ }^{11} \mathrm{~B}$, ${ }^{25} \mathrm{Mg}$ and ${ }^{139} \mathrm{La}$ being analysed at low resolution, and ${ }^{7} \mathrm{Li},{ }^{11} \mathrm{~B}, \mathrm{Na},{ }^{25} \mathrm{Mg}, \mathrm{Al}$ and ${ }^{28} \mathrm{Si}$ analysed at medium resolution. $A$ set of four multielement standards containing $0.0,0.5,5.0$ and $50.0 \mathrm{ng} / \mathrm{ml}$ of $B$ and $\mathrm{Li}$, and $0.0,0.05$, 0.5 and $5.0 \mathrm{ng} / \mathrm{ml}$ of Al, La, Mg, Na and Si were analysed before and after the samples. All standards contained isotopes at natural abundance.

Samples were analysed in sets of seven, with each set of samples and set of four multi-element standards being bracketed by two multi-element standard measurements of $5.0 \mathrm{ng} / \mathrm{ml}$ of $B$ and $\mathrm{Li}$, and $0.5 \mathrm{ng} / \mathrm{ml}$ of all other 
elements. The first set of four multi-element standards was used to create calibration curves. All blanks contained less than $0.05 \mathrm{ng} / \mathrm{ml}$ of $\mathrm{Li}$ and $\mathrm{B}$, $0.5 \mathrm{ng} / \mathrm{ml} \mathrm{Al}, 1.5 \mathrm{ng} / \mathrm{ml} \mathrm{Si}$ excluding 2 outliers, $0.15 \mathrm{ng} / \mathrm{ml} \mathrm{Na}$ and $0.75 \mathrm{ng} /$ $\mathrm{ml} \mathrm{Mg}$. Sample concentrations were corrected for background concentrations, drift corrected, normalised to their first bracketing standard concentration and then corrected for the dilution factor used. The high background associated with Si meant that the 0.05 and $0.5 \mathrm{ng} / \mathrm{ml}$ standards were below detection limits. Therefore, although many of the Si readings were above the detection limit, these values were considered unreliable as they were created from a single-point calibration. The concentrations of $\mathrm{Li}, \mathrm{B} \mathrm{Na}$ and $\mathrm{Mg}$ in the leachates were well above their respective detection limits, while the concentrations of La and Al were not.

\section{Leachate concentration data treatment}

The corrected concentrations of element $i$ in solution, $C_{i}^{\text {Sample }}$, were then used with the initial leachant volume, $V_{i}$, the mass of glass powder leached, $m$, and the elemental mass fraction of $i$ within the glass, $f_{i}$, to calculate the estimated fraction of $i$ leached from the glass, $L F_{i}$, using Equation 1.

$L F_{i}=\frac{C_{i}^{\text {Sample }} \cdot v_{i}}{m \cdot f_{i}}$

From the leached fraction of $B$, an average alteration layer thickness, $t$, could be calculated using Equation 2. This equation was based on the shrinking core model assuming pristine spherical glass particles of median radius $\left(r_{0}=56.25 \mu \mathrm{m}\right)$ were uniformly altered. ${ }^{38}$

$t=r_{0}\left(1-\sqrt[3]{\left(1-L F_{B}\right)}\right)$

\section{Alkali fusion and HF digestion}

Four sets of $50 \mathrm{mg}$ of pristine washed and sized ${ }^{6} \mathrm{Li}-\mathrm{Mg}$-EM powders underwent alkali fusion using $250 \mathrm{mg}$ of $\mathrm{K}_{2} \mathrm{CO}_{3}$ following a fusion methodology originally designed for natural samples. ${ }^{39}$ These fusion supernatants were then analysed via ICP-OES (Agilent 5100) and Li recoveries for the alkali fusion process alone were found to be between 84 and $95 \%$. These supernatants were then diluted 100 times using $2 \% \mathrm{HNO}_{3}$ before being prepared for column chromatography.

The accuracy of the pristine glass isotopic composition obtained through the alkali fusions was verified through HF digestion: $15.0 \mathrm{mg}$ of washed and sized ${ }^{6} \mathrm{Li}-\mathrm{Mg}$-EM powder was digested in $0.7 \mathrm{ml}$ single distilled $\mathrm{HF}$ and $0.5 \mathrm{ml}$ double distilled $\mathrm{HNO}_{3}$ at $150^{\circ} \mathrm{C}$ for $24 \mathrm{~h}$. In this time, the glass was noted to have completely dissolved. The digest was then dried down, before being taken up in $1 \mathrm{ml}$ double distilled aqua regia at $150^{\circ} \mathrm{C}$ for $24 \mathrm{~h}$ then dried down again. This procedure was then repeated twice more using double distilled $6 \mathrm{~N} \mathrm{HCl}$, but on the final time was not dried down.

\section{Column chromatography}

The samples were subjected to cation exchange column chromatography to prepare purified mono-elemental Li solutions through matrix separation for MC-ICP-MS analysis. All HCl used for dilutions and column chromatography had been double distilled using a Teflon sub-boiling still and calibrated at $0.7 \mathrm{~N}$ using titrations with $1.0 \mathrm{M}$ of $\mathrm{NaOH}$ (Fisher Scientific, certified grade). Twelve $3 \mathrm{ml}$ Teflon high aspect ratio ion exchange columns, with a length of $250 \mathrm{~mm}$ and an internal diameter of $4 \mathrm{~mm}$, containing AG MP-50 macroporous cation exchange resin were used. For the leachates and alkali fusions, sample volumes containing $300 \mathrm{ng} \mathrm{Mg}$ (leachates) or $4 \mathrm{ng} \mathrm{Li}$ (alkali fusions) were dried down in PFA vials at $80^{\circ} \mathrm{C}$, refluxed in double distilled concentrated $\mathrm{HNO}_{3}$, dried down again and taken up in $200 \mu \mathrm{l}$ of $0.7 \mathrm{~N} \mathrm{HCl}$ for loading on the column. The HF digest in $6 \mathrm{~N} \mathrm{HCl}$ was instead diluted using $0.7 \mathrm{~N} \mathrm{HCl}$ to a nominal Li concentration of $20 \mathrm{ng} / \mathrm{ml}$, before $200 \mu \mathrm{l}$ ( $4 \mathrm{ng} \mathrm{Li}$ ) was loaded onto the columns in duplicate. The methodology used for column chromatography did not differ from that described in the original methodology for the leachates, ${ }^{25}$ but a $15 \mathrm{ml} \mathrm{Li}$ cut $(2 \mathrm{ml}$ more than the original methodology, with the initial matrix elution being $2 \mathrm{ml}$ less) was used for the alkali fusions and $\mathrm{HF}$ digests. After the column elutions with $0.7 \mathrm{~N} \mathrm{HCl}$, the methodology of which is described in great detail in the original publication, ${ }^{25}$ the $\mathrm{Li}$ fractions were again dried down, refluxed in concentrated $\mathrm{HNO}_{3}$ and after drying down once more were taken up in $0.5 \mathrm{ml}$ (leachates) or $1.0 \mathrm{ml}$ (alkali fusions and digests) $2 \% \mathrm{HNO}_{3}$ for isotopic analysis. $\delta^{7} \mathrm{Li}$ analyses

For the leachates, the volumes of the $\mathrm{Li}$ fractions and $2 \% \mathrm{HNO}_{3}$ required to yield $9 \mathrm{ng} / \mathrm{ml}$ of Li were dispensed into acid cleaned $2 \mathrm{mI}$ PFA ICP vials. $\delta^{7} \mathrm{Li}$ analysis took place on a multicollector ICP-MS (MC-ICP-MS, Thermo Scientific Neptune Plus) at low resolution. Samples were introduced using a quartz Apex-IR (ESI) system with $140^{\circ} \mathrm{C}$ spray chamber with $2^{\circ} \mathrm{C}$ Peltier coil. A Savillex PFA $100 \mu \mathrm{l} / \mathrm{min}$ nebuliser with Ni-Jet sample and Ni-X type skimmer cones were used. Cups $\mathrm{L} 4$ and $\mathrm{H} 4$ were used with $10^{11} \Omega$ preamplifiers to measure ${ }^{6} \mathrm{Li}$ and ${ }^{7} \mathrm{Li}$, respectively. Measurements were composed one block of 30 cycles with an integration time of $8.4 \mathrm{~s}$, and were taken with respect to and bracketed by NIST SRM 8545 L-SVEC $^{40}$ at a concentration of $9 \mathrm{ng} / \mathrm{ml}$. Analyte measurements were corrected for instrumental mass bias and drift during analysis using a standard-sample bracketing technique with the L-SVEC standard. ${ }^{10,25,41}$ Li7-N, ${ }^{42}$ also at a concentration of $9 \mathrm{ng} / \mathrm{ml}$, was analysed at the beginning and end of each set of nine samples and L-SVEC standard measurements as a secondary standard. A blank $\left(2 \% \mathrm{HNO}_{3}\right)$ was measured after each standard or sample measurement, with typical blank concentrations of $\sim 0.015 \mathrm{ng} / \mathrm{ml}$. Each sample was measured in duplicate, with samples being rerun again throughout the analysis to confirm reproducibility.

For the alkali fusions, the same instrument, Apex-IR (ESI) nebuliser and cones were used as for the leachates. However, ${ }^{7} \mathrm{Li}$ and ${ }^{6} \mathrm{Li}$ were instead measured using $10^{13} \Omega$ amplifiers. Samples were diluted to a target concentration of $0.7 \mathrm{ng} / \mathrm{ml}$ using $2 \% \mathrm{HNO}_{3}$ and analysed alongside NIST SRM 8545 L-SVEC at the same concentration to bracket each sample measurement, with each sample analysed in triplicate. A $5 \mathrm{ng} / \mathrm{ml} \mathrm{Ca} \mathrm{wash}$ was used between each measurement to minimise the Li background, with typical blank backgrounds of $\sim 0.007 \mathrm{ng} / \mathrm{ml}$; two orders of magnitude lower than those of the standards and samples. Li6-N and Li7-N standards were again analysed at the beginning of the run to assess external reproducibility at a concentration of $0.7 \mathrm{ng} / \mathrm{ml}{ }^{42}$ The $\mathrm{HF}$ digests were analysed following the same procedure as the alkali fusions, except each $\mathrm{Li}$ fraction was analysed in duplicate at $0.56 \mathrm{ng} / \mathrm{ml}$ rather than in triplicate at $0.7 \mathrm{ng} / \mathrm{ml}$.

The blank corrected sample ${ }^{7} \mathrm{Li} /{ }^{6} \mathrm{Li}$ were converted to $\delta^{7} \mathrm{Li}(\%)$ with respect to the average of the two blank corrected bracketing L-SVEC standard ${ }^{7} \mathrm{Li} /{ }^{6} \mathrm{Li}$ measurements using Equation 3:

$\delta^{7} L i_{\text {sample }}=\left(\frac{\frac{{ }^{7} L i}{{ }^{6} i_{\text {sample }}}}{\frac{1}{2}\left(\frac{{ }^{7} L i}{{ }^{6} \text { istandard }_{1}}+\frac{{ }^{\prime} L i}{{ }^{6} i_{\text {standard }}}\right)}-1\right) \times 1000$

A $\delta^{7} \mathrm{Li}$ for each sample was then calculated as the average $\delta^{7} \mathrm{Li}$ of the duplicate or triplicate sample measurements and interpolated $\delta^{7} \mathrm{Li}$ values calculated between each pair of blank corrected sample measurements and the blank corrected L-SVEC standard ${ }^{7} \mathrm{Li} /{ }^{6} \mathrm{Li}$ measured between them. Errors $(2 \sigma)$ were calculated as twice the standard deviation of the blankcorrected duplicate sample measurements and the interpolated-blanks $\delta^{7} \mathrm{Li}$ value measured between them. An average $\delta^{7} \mathrm{Li}$ of $-916.5 \pm 0.3 \%$ o was measured for the four full-procedure replicate $\mathrm{K}_{2} \mathrm{CO}_{3}$ fusions of the pristine ${ }^{6} \mathrm{Li}-\mathrm{Mg}-\mathrm{EM}$ glass. The $\delta^{7} \mathrm{Li}$ of the digest was found to be in excellent agreement with that of $\mathrm{K}_{2} \mathrm{CO}_{3}$ fusions at $-916.4 \pm 0.1 \%$ ond confirmed the accuracy of the $\mathrm{K}_{2} \mathrm{CO}_{3}$ methodology. ${ }^{39}$

\section{${ }^{6} \mathrm{Li}-{ }^{1} \mathrm{H}$ cross polarisation nuclear magnetic resonance}

A sample of the same target composition as ${ }^{6} \mathrm{Li}-\mathrm{Mg}-\mathrm{EM}$, without isotopic enrichment which had been leached in a separate study, underwent ${ }^{6} \mathrm{Li}-{ }^{1} \mathrm{H}$ cross polarisation nuclear magnetic resonance (CP-NMR) analysis. ${ }^{31}$ This sample had been leached for 7 days in deionised water at $90^{\circ} \mathrm{C}$ at a SA/V of $2000 \mathrm{~m}^{-1}$. However, experiments were ended entirely rather than just sampled at each sampling interval. A pristine sample was also analysed to demonstrate there was no measurable signal (polarisation) transferred from ambient proton absorption on to the glass. Approximately $130 \mathrm{mg}$ of sample was loaded into a PTFE liner inside a $7.5 \mathrm{~mm}$ zirconia rotor, which was placed into a $7.5 \mathrm{~mm}$ double resonance MAS probe but not spun. A spectrometer frequency of $499.72 \mathrm{MHz}$ for ${ }^{1} \mathrm{H}$ and $73.54 \mathrm{MHz}$ for ${ }^{6} \mathrm{Li}$ were used. A $\pi / 2$ pulse $(8.0 \mu \mathrm{s})$ was found for ${ }^{1} \mathrm{H}$ using RTV silicone and a pulse delay of $3 \mathrm{~s}$ was used. Powdered $\mathrm{LiOH}$ was used to optimise matching conditions and contact time. Spectra were collected with between 75,000 and 250,000 repetitions under the conditions above and were referenced to ${ }^{6} \mathrm{Li}$ in a $1.0 \mathrm{M}{ }^{6} \mathrm{LiCl}\left(95.77 \%{ }^{6} \mathrm{Li}\right.$ atoms) solution at $0.0 \mathrm{ppm}$. 


\section{DATA AVAILABILITY}

The data that support the findings of this study are available in Apollo, the University of Cambridge institutional repository with the identifier https://doi.org/10.17863/ CAM.45721 (ref. ${ }^{43}$ ).

Received: 12 July 2019; Accepted: 5 November 2019; Published online: 22 November 2019

\section{REFERENCES}

1. Gin, S. et al. The controversial role of inter-diffusion in glass alteration. Chem. Geol. 440, 115-123 (2016).

2. Geisler, T. et al. The mechanism of borosilicate glass corrosion revisited. Geochim. Cosmochim. Acta 158, 112-129 (2015).

3. Hellmann, R. et al. Nanometre-scale evidence for interfacial dissolutionreprecipitation control of silicate glass corrosion. Nat. Mater. 14, 307-311 (2015).

4. Geisler, T. et al. Aqueous corrosion of borosilicate glass under acidic conditions: a new corrosion mechanism. J. Non. Cryst. Solids 356, 1458-1465 (2010).

5. Doremus, R. H. Interdiffusion of hydrogen and alkali ions in a glass surface. J. Non. Cryst. Solids 19, 137-144 (1975).

6. Doremus, R. H. Interdiffusion of alkali and hydronium ions in glass: partial ionization. J. Non. Cryst. Solids 48, 431-436 (1982).

7. Frugier, P. et al. SON68 nuclear glass dissolution kinetics: current state of knowledge and basis of the new GRAAL model. J. Nucl. Mater. 380, 8-21 (2008).

8. Busby, J. P., Lee, J. R., Kender, S., Williamson, J. P. \& Norris, S. Modelling the potential for permafrost development on a radioactive waste geological disposal facility in Great Britain. Proc. Geol. Assoc. 126, 664-674 (2015).

9. Gin, S., Ryan, J. V., Schreiber, D. K., Neeway, J. \& Cabié, M. Contribution of atomprobe tomography to a better understanding of glass alteration mechanisms: application to a nuclear glass specimen altered 25 years in a granitic environment. Chem. Geol. 349-350, 99-109 (2013).

10. Penniston-Dorland, S., Liu, X.-M. \& Rudnick, R. L. Lithium isotope geochemistry. Rev. Mineral. Geochem. 82, 165-217 (2017).

11. Vigier, N. et al. Quantifying $\mathrm{Li}$ isotope fractionation during smectite formation and implications for the Li cycle. Geochim. Cosmochim. Acta 72, 780-792 (2008).

12. Kim, J., Nielsen, U. G. \& Grey, C. P. Local environments and lithium adsorption on the iron oxyhydroxides lepidocrocite $(\gamma-\mathrm{FeOOH})$ and goethite $(\mathrm{a}-\mathrm{FeOOH})$ : a ${ }^{2} \mathrm{H}$ and ${ }^{7} \mathrm{Li}$ solid-state MAS NMR study. J. Am. Chem. Soc. 130, 1285-1295 (2008).

13. James, R. \& O'Neil Theoretical and experimental aspects of isotopic fractionation. Rev. Mineral. 16, 1-40 (1986).

14. Pistiner, J. S. \& Henderson, G. M. Lithium-isotope fractionation during continental weathering processes. Earth Planet. Sci. Lett. 214, 327-339 (2003).

15. Huh, Y., Chan, L. H. \& Chadwick, O. A. Behavior of lithium and its isotopes during weathering of Hawaiian basalt. Geochem. Geophys. Geosyst. 5, 1-22 (2004).

16. Wimpenny, J. et al. The behaviour of $\mathrm{Li}$ and $\mathrm{Mg}$ isotopes during primary phase dissolution and secondary mineral formation in basalt. Geochim. Cosmochim. Acta 74, 5259-5279 (2010).

17. Schauble, E. A. Applying stable isotope fractionation theory to new systems. Rev. Mineral. Geochem. 55, 65-111 (2004).

18. Hindshaw, R. S. et al. Experimental constraints on Li isotope fractionation during clay formation. Geochim. Cosmochim. Acta 250, 219-237 (2019).

19. Misra, S. \& Froelich, P. N. Lithium isotope history of cenozoic. Science $\mathbf{3 3 5}$, 818-824 (2012)

20. Seyfried, W. E., Chen, X. \& Chan, L. H. Trace element mobility and lithium isotope exchange during hydrothermal alteration of seafloor weathered basalt: an experimental study at $350^{\circ} \mathrm{C}, 500$ bars. Geochim. Cosmochim. Acta 62, 949-960 (1998).

21. Kisakurek, B., James, R. H. \& Harris, N. B. W. Li and $\delta^{7}$ Li in Himalayan rivers: proxies for silicate weathering? Earth Planet. Sci. Lett. 237, 387-401 (2005).

22. Williams, L. B. \& Hervig, R. L. Lithium and boron isotopes in illite-smectite: the importance of crystal size. Geochim. Cosmochim. Acta 69, 5705-5716 (2005).

23. Chan, L. H., Edmond, J. M., Thompson, G. \& Gillis, K. Lithium isotopic composition of submarine basalts: implications for the lithium cycle in the oceans. Earth Planet. Sci. Lett. 108, 151-160 (1992).

24. Chan, L. H., Alt, J. C. \& Teagle, D. A. H. Lithium and lithium isotope profiles through the upper oceanic crust: A study of seawater-basalt exchange at ODP Sites 504B and 896A. Earth Planet. Sci. Lett. 201, 187-201 (2002).

25. Bohlin, M. S., Misra, S., Lloyd, N., Elderfield, H. \& Bickle, M. J. High precision determination of lithium and magnesium isotopes utilising single column separation and MC-ICPMS. Rapid Commun. Mass Spectrom. 32, 93-104 (2018).
26. Guo, R., Brigden, C. T., Gin, S., Swanton, S. W. \& Farnan, I. The effect of magnesium on the local structure and initial dissolution rate of simplified UK Magnox waste glasses. J. Non. Cryst. Solids 497, 82-92 (2018).

27. Palmer, M. R., Spivack, A. J. \& Edmond, J. M. Temperature and pH controls over isotopic fractionation during adsorption of boron on marine clay. Geochim. Cosmochim. Acta 51, 2319-2323 (1987).

28. Gin, S. et al. Origin and consequences of silicate glass passivation by surface layers. Nat. Commun. 6, 6360 (2015).

29. Gin, S., Beaudoux, X., Angeli, F., Jegou, C. \& Godon, N. Effect of composition on the short-term and long-term dissolution rates of ten borosilicate glasses of increasing complexity from 3 to 30 oxides. J. Non. Cryst. Solids 358, 2559-2570 (2012).

30. Goût, T. L., Harrison, M. T. \& Farnan, I. Relating Magnox and international waste glasses. J. Non. Cryst. Solids 524, 119647 (2019).

31. Goût, T. L., Harrison, M. T. \& Farnan, I. Impacts of lithium on Magnox waste glass dissolution. J. Non. Cryst. Solids 517, 96-105 (2019).

32. Hopf, J. et al. Toward an understanding of surface layer formation, growth, and transformation at the glass-fluid interface. Geochim. Cosmochim. Acta 229, 65-84 (2018).

33. Curti, E., Crovisier, J. L., Morvan, G. \& Karpoff, A. M. Long-term corrosion of two nuclear waste reference glasses (MW and SON68): a kinetic and mineral alteration study. Appl. Geochem. 21, 1152-1168 (2006).

34. Rebiscoul, D., Frugier, P., Gin, S. \& Ayral, A. Protective properties and dissolution ability of the gel formed during nuclear glass alteration. J. Nucl. Mater. 342, 26-34 (2005).

35. Gin, S. et al. Dynamics of self-reorganization explains passivation of silicate glasses. Nat. Commun. 9, 2169 (2018).

36. Gin, S. et al. An international initiative on long-term behavior of high-level nuclear waste glass. Mater. Today 16, 243-248 (2013).

37. ASTM. Standard Test Methods for Determining Chemical Durability of Nuclear, Hazardous, and Mixed Waste Glasses and Multiphase Glass Ceramics: The Product Consistency Test (PCT) Designation: C1285-14. ASTM, Conshohocken, USA (2002). https://doi.org/10.1520/C1285-14.2

38. Jégou, C., Gin, S. \& Larché, F. Alteration kinetics of a simplified nuclear glass in an aqueous medium: effects of solution chemistry and of protective gel properties on diminishing the alteration rate. J. Nucl. Mater. 280, 216-229 (2000).

39. Lemarchand, D., Cividini, D., Turpault, M. P. \& Chabaux, F. Boron isotopes in different grain size fractions: Exploring past and present water-rock interactions from two soil profiles (Strengbach, Vosges Mountains). Geochim. Cosmochim. Acta 98, 78-93 (2012).

40. Flesch, G. D., Anderson, A. R. \& Svec, H. J. A secondary isotopic standard for ${ }^{6} \mathrm{Li} /{ }^{7} \mathrm{Li}$ determinations. Int. J. Mass Spectrom. Ion Phys. 12, 265-272 (1973).

41. Misra, S. \& Froelich, P. N. Measurement of lithium isotope ratios by quadrupoleICP-MS: application to seawater and natural carbonates. J. Anal. At. Spectrom. 24, 1524-1533 (2009).

42. Carignan, J., Vigier, N. \& Millot, R. Three secondary reference materials for lithium isotope measurements: Li7-N, Li6-N and LiCl-N solutions. Geostand. Geoanal. Res. 31, 7-12 (2007).

43. Goût, T. L. et al. Diffusive processes in aqueous glass dissolution. Apollo, University of Cambridge institutional repository. https://doi.org/10.17863/ CAM.45721 (2019).

\section{ACKNOWLEDGEMENTS}

We thank Victoria Gony, Giulio Lampronti and Iris Buisman for their technical support. The authors acknowledge financial support from EPSRC under an Industrial CASE award with the NDA (EP/M507350/1).

\section{AUTHOR CONTRIBUTIONS}

T.G. fabricated the glass, began the dissolution experiments, sampled the aliquots, alkali fused the glass, HF digested the glass, prepared samples for concentration and isotope analyses, assisted in analysing the leachates, interpreted the results and wrote the manuscript. S.M. supervised the isotope work, analysed the leachates and assisted in interpreting the results. E.T. arranged and supervised the alkali fusion, analysed the digested samples and supervised their digestion and assisted in interpreting the results. M.B. analysed the alkali fused glass, digested the glass in the first instance, supervised and assisted in column chromatography, and assisted in interpreting the results. R.G. assisted in acquiring the NMR spectrum and interpreting the results. I.F. conceived the experiments, supervised the study and assisted in interpreting the results. 


\section{COMPETING INTERESTS}

The authors declare no competing interests.

\section{ADDITIONAL INFORMATION}

Supplementary information is available for this paper at https://doi.org/10.1038/ s41529-019-0102-5.

Correspondence and requests for materials should be addressed to T.L.G.

Reprints and permission information is available at http://www.nature.com/ reprints

Publisher's note Springer Nature remains neutral with regard to jurisdictional claims in published maps and institutional affiliations.
Open Access This article is licensed under a Creative Commons Attribution 4.0 International License, which permits use, sharing, adaptation, distribution and reproduction in any medium or format, as long as you give appropriate credit to the original author(s) and the source, provide a link to the Creative Commons license, and indicate if changes were made. The images or other third party material in this article are included in the article's Creative Commons license, unless indicated otherwise in a credit line to the material. If material is not included in the article's Creative Commons license and your intended use is not permitted by statutory regulation or exceeds the permitted use, you will need to obtain permission directly from the copyright holder. To view a copy of this license, visit http://creativecommons. org/licenses/by/4.0/.

(c) The Author(s) 2019 